\title{
Urdimento
}

Revista de Estudos em Artes Cênicas

E-ISSN: 2358.6958

\section{Trilogia do corpo no espaço: influências da prática de escalada na criação cênica em dança}

Cláudia Regina Garcia Millás

\section{Para citar este artigo:}

MILLÁS, Cláudia Regina Garcia. Trilogia do corpo no espaço: influências da prática de escalada na criação cênica em dança. Urdimento, Florianópolis, v. 2, n. 38, ago./set. 2020.

DOI: http:/dx.doi.org/10.5965/14145731023820200006

Este artigo passou pelo Plagiarism Detection Software | iThenticate 
Trilogia do corpo no espaço: influências da prática de escalada na criação cênica em dança

Cláudia Regina Garcia Millás

\begin{abstract}
Resumo
Apresenta-se neste artigo a descrição e análise de três obras de dança autorais que podem ser vistas como uma trilogia de abordagem do corpo no espaço a partir do uso de uma parede em cena, tendo a prática da escalada como principal fonte de inspiração e elemento propulsor para a criação cênica. Investiga-se o espaço vertical enquanto fator de a(fe)tivação, por mobilizar e afetar, tanto ao artista em cena quanto ao público que assiste a obra. Observa-se que o espaço em questão permite ao praticante adentrar num lugar incomum e experienciar o fluxo, que exige engajamento corporal e integridade, aguçando a sensibilidade e possibilitando outras maneiras de ver e viver o mundo. Desta forma, as propostas analisadas buscaram criar outros pontos de vista, gerando estranheza no olhar, para que se pudesse ver com mais atenção, tendo-se diferentes leituras das criações apresentadas.
\end{abstract}

Palavras-chave: Dança. Espaço. Criação cênica. Escalada.

\title{
Trilogy of the body in space: influences of climbing practice on scenic creation in dance
}

\begin{abstract}
This article presents the description and analysis of three authorial dance works that can be seen as a trilogy of approaching the body in space from the use of a wall on stage, with the practice of climbing as the main source of inspiration and propelling element for scenic creation. The vertical space is investigated as a factor of a(fe)tivation, for mobilizing and affecting both the artist on stage and the audience watching the work. It is observed that the space in question allows the practitioner to enter an unusual place and experience the flow, which requires bodily engagement and integrity, sharpening sensitivity and enabling other ways of seeing and living the world. In this way, the analyzed proposals sought to create other points of view, generating strangeness in the look, so that one could see with more attention, having different readings of the creations presented.
\end{abstract}

Keywords: Dance. Space. Scenic creation. Climbing.

Doutorado em Artes Cênicas (UNIRIO). Docente no Departamento de Arte Corporal da Escola de Educação Física e Desportos da Universidade Federal do Rio de Janeiro (UFRJ). claudinhamillas@hotmail.com 
Trilogía del cuerpo en el espacio: influencias de la práctica de la escalada en la creación escénica en la danza

\section{Resumen}

Este artículo presenta la descripción y el análisis de tres obras de danza del autor que pueden considerarse como una trilogía que trata sobre el cuerpo en el espacio a partir del uso de una pared en el escena, con la práctica de la escalada como principal fuente de inspiración y elemento propulsor de la creación escénica. El espacio vertical se investiga como un factor de a(fe)tivación, para movilizar y afectar tanto al artista en el escenario como al público que observa la obra. Se observa que el espacio en cuestión permite al practicante entrar en un lugar insólito y experimentar el flujo, lo que requiere un compromiso y una integridad corporal, agudizando la sensibilidad y posibilitando otras formas de ver y vivir el mundo. De esta manera, las propuestas analizadas buscaban crear otros puntos de vista, generando extrañeza en la mirada, de manera que se pudiera ver con más atención, teniendo diferentes lecturas de las creaciones presentadas.

Palabras clave: Danza. Espacio. Creación escénica. Escalada. 
Apresenta-se neste artigo a análise e descrição de três obras de dança autorais enquanto abordagens do corpo no espaço vertical a partir do uso de uma parede em cena, revelando influências da prática da escalada nas composições em suas particularidades estéticas e expressivas.

Concebem-se estas obras como uma trilogia por pertencerem ao mesmo autor e tratarem de um mesmo tema de investigação acerca do espaço vertical e apropriação do elemento parede em cena, percebendo-se a contaminação e transformação de um trabalho para outro. Busca-se descrever cada obra desde o processo criativo, a partir das motivações do autor, até as reverberações nos momentos de partilha e relações com o público. Analisa-se o percurso trilhado e os possíveis sentidos criados em cada trabalho. Justifica-se pela carência de materiais de investigação sobre o tema, em que a dança e o espaço vertical se encontram na criação cênica.

Trata-se a parede de um espaço vertical, que não é comum aos homens, sendo necessários aparatos, técnicas e treinamentos específicos para seu uso e apropriação. Ao habitá-la envolve-se o praticante em um lugar de risco, que exige atenção e concentração, conforme explicitado por Millás (2014). Percebe-se a parede enquanto fator de a(fe)tivação, que tanto mobiliza, exigindo atenção ao momento, quanto afeta, permitindo que artista e público possam ser deslocados de seu lugar comum, vendo a si e ao mundo sob outra perspectiva.

O espaço vertical propicia ao participante adentrar numa experiência de fluxo, em consonância com a teoria delineada por Mihaly Csikszentmihalyi (2002), em que se revela uma vivência tão intensa que somente a ela pode-se responder, em concentração plena e engajamento corporal que fazem com que o praticante possivelmente se esqueça de si mesmo ao longo da atividade e, ao final, se sinta mais conectado ao meio que vive, percebendo-se potente corporalmente e com os sentidos aguçados.

A distinção plausível entre lugar, como parte objetiva, e espaço, parte afetiva, proposta pela autora Laurence Louppe (2012), se faz presente e instaura outra forma de pensar e estar nos trabalhos em questão. A parede, como um lugar que 
não é comum habitar, contém um tipo de espaço mobilizador, com tensões particulares, que fazem o bailarino vibrar de uma determinada forma. São estas tensões, forças invisíveis, mas perceptíveis, que atravessam o bailarino em cena e o fazem dançar. Neste sentido, Rudolf Laban (1984) já analisava não somente o movimento dos corpos no espaço, mas o movimento do espaço nos corpos, deixando claro o caráter afetivo e propulsor, a que se refere Louppe: "O espaço move-se através de nós, mas também em nós." (Louppe, 2012, p. 189).

Destacam-se dois treinamentos necessários para que se faça possível habitar o espaço vertical mencionado. Um deles seria um treinamento físico, que não só garante que a prática se torne segura, quanto possível. Pois não estaria qualquer bailarino apto a subir ou dançar numa parede, tornando este espaço seu campo de atuação, capaz de experimentar outras possibilidades de movimentação decorrentes do uso diferenciado do peso e eixo do corpo. Para experienciar este lugar incomum, deve-se desenvolver um trabalho corporal específico com fortalecimento dos membros superiores - não somente dos braços, mas cada dedo das mãos, para apoio e sustentação do peso corporal - além de ativação do centro de força, que tornaria o corpo mais leve. Também se evidencia a necessidade de conhecimento do funcionamento dos diversos materiais e aparelhos, quando utilizados, que se tornam parceiros da prática, criando-se intimidade a partir de seu manuseio e domínio.

O outro treinamento seria da ordem da experiência, do campo dos afetos, que permitiria ao praticante se envolver na atividade e se deixar ser atravessado por este campo de forças referido. Diferentemente da atuação dos escaladores, utilizar-se-ia a parede para dançar e criar uma composição cênica, e não somente para subir e descer. Portanto, desenvolver a escuta, aguçar os sentidos e criar abertura para o momento, se torna fundamental.

Ainda mais adequado seria falar de treinamentos, no plural, como um conjunto de práticas e condutas que tornariam possível experienciar este espaço incomum e utilizá-lo como fator de a(fe)tivação. 
Investiga-se de que forma a prática da escalada vivenciada pelo autor influenciou diretamente nas obras criadas, tendo despertado um interesse tanto no espaço de atuação, apropriando-se do elemento parede enquanto lugar incomum, quanto nas transformações corporais geradas que agregavam uma qualidade particular. Percebeu-se que o espaço vertical proporcionava adentrar na experiência de fluxo, já mencionada, em que os praticantes podiam ver a si e ao mundo de outra forma, deixando uma concepção pré-estabelecida de lado para que outras pudessem ser criadas.

Considerando a escalada não como uma única atividade, mas como um conjunto de práticas heterogêneas, cada qual com suas próprias regras, espaços de atuação, participantes e objetivos (Flores, 1978), contextualiza-se as práticas que foram utilizadas em cada trabalho cênico criado. Em Ao Vestir Vertigens, primeira obra a ser analisada, apropriou-se especificamente da escalada indoor, realizada em ambiente artificial, utilizando-se a parede externa de um prédio como palco de atuação, contendo em si aspectos cenográficos e potencializadores para a criação, que serão destrinchados a seguir. Por se tratar de um trabalho coletivo, onde esteve envolvido um grupo de bailarinos, serão utilizados os relatos de experiência por eles elaborados, para se fazer uma análise e descrição do processo de criação empreendido. Além disso, por se tratar de uma obra processual, em que cada ensaio poderia ser considerado como uma mostra, já que se utilizava de uma parede externa de um prédio, voltada para rua onde passavam diversos transeuntes, serão igualmente analisadas as reações, comentários e diálogos com o "público" presente.

Já nos trabalhos seguintes, Ausência/Presença e Sobre o que desaba e que não sei dizer, a maior influência esteve na escalada em ambiente natural, mais precisamente a tradicional brasileira, consonante com as denominações apresentadas por Cintia e Flávio Daflon (2016), quando o escalador interage com a rocha em suas mais diversas composições e condições, metamorfoseando-se com ela. Da mesma forma, no último trabalho a ser analisado, em que foram realizados bate-papos com público a cada apresentação, serão utilizados os comentários e impressões partilhados para possível análise das leituras 
empreendidas, verificando de que forma o espaço também a(fe)tivou os espectadores.

No universo da escalada, pode-se escutar com alguma frequência que a subida vertical se assemelha a uma espécie de coreografia, em que o escalador estaria dançando ao progredir na parede, tanto artificial quanto natural. No entanto, há de se questionar se esta inferência refere-se ao aspecto formal e visível da dança, quanto à execução dos movimentos apresentados, ou à parte invisível relativa às forças e agenciamentos presentes (ou a ambos os casos).

$\mathrm{Na}$ primeira possibilidade, poder-se-ia conceber o trajeto da escalada, denominado de via, como uma proposta coreográfica literalmente, em que o escalador segue a concepção de outra pessoa, que seria o conquistador daquela rota, tornando-se intérprete da "obra", ou como improvisador criando soluções aos problemas apresentados. Já na segunda possibilidade, poder-se-ia percebê-lo como campo de forças que promoveria um acontecimento, num nível sutil e sensível.

Autores como Sally Ann Ness (2016), que descreve a escalada a partir de sua experiência no Parque Nacional de Yosemite, nos Estados Unidos, trazem outros aspectos que não só formais e organizacionais. Para Ness (2016) a escalada não seria uma questão coreográfica, mas de um agenciamento de forças, que criaria uma dança excêntrica. Os problemas que a escalada colocaria seriam resolvidos por cada participante no momento da ação, exigindo uma força outra e gerando uma sensação de liberdade. Michel Serres (2004) refere-se à montanha, ambiente da escalada em meio natural, como espaço que requer honestidade e sinceridade consigo mesmo, que revela a realidade e que não tolera ajustes. Necessita que o escalador se coloque de forma precisa e que esteja ativo, com o corpo todo em movimento, engajado na ação, para que possa correr o risco necessário, tornando a prática possível e de certo modo segura.

Seria na relação com o espaço que se conseguiria chegar a uma experiência do corpo-em-fluxo, termo cunhado para referir-se à interação entre a teoria de fluxo proposta por Mihaly Csikszentmihalyi (2002) e o entendimento de corpo em 
movimento apresentado por Michel Serres (2004), trazendo a possibilidade de se pensar em qualidades corporais específicas que permitem ao praticante transformar-se ao longo da ação, quando, aberto e disponível ao momento, em escuta aos sussurros do espaço, sendo atravessado pelas diversas forças existentes, seria conduzido, dançado pelo instante, tornando-se parte do ambiente que habita.

No primeiro trabalho, Ao Vestir Vertigens, encontram-se aspectos composicionais estéticos nos quais o espaço vertical foi utilizado como fonte de criação. Em Ausência/Presença o traço mais forte é a investigação do que gera o corpo no espaço, e vice-versa, como um campo de força criado, e dos rastros deixados. E por fim, em Sobre o que desaba e que não sei dizer, o uso da parede é evidente, como herança do primeiro trabalho com o espaço vertical, mas já com intenções de revelar outras formas de abordagem, percebendo que ao alterar a perspectiva do espaço não era somente a ação que se deslocava e era vista de outra forma, mas o próprio público sentia-se deslocado.

\section{Ao Vestir Vertigens ${ }^{2}$}

A coreógrafa e bailarina norte americana Trisha Brown, nascida em 1936 e falecida em 2017, fundadora da Trisha Brown Dance Company, com a qual desenvolveu uma série de trabalhos artísticos expostos e apresentados em diversas regiões do mundo, revela em suas primeiras obras denominadas Early Works e Equipament Pieces, criadas entre 1966 e 1975, estudos de apropriação do espaço vertical, utilizando-se de fachadas de prédios, paredes de galerias, pilastras estruturais de edifícios, tronco de árvores e estruturas específicas para suportar os bailarinos em cena.

No contexto da dança pós-moderna americana, num movimento de contracultura difundido na cidade de Nova Iorque nos anos 60, os artistas traziam

Para maiores informações sobre este trabalho, com vídeos e fotos, pode-se acessar o link: https://claudiamillas.wordpress.com/espetaculos/coletivo-invertido/ao-vestir-vertigens/. 
para a dança ações ordinárias simples, como correr, caminhar, saltar e cair, mas deslocadas de seu lugar original, sendo realizadas em circunstâncias extraordinárias. Trisha Brown, como umas das precursoras deste movimento, realizou uma série de experimentações corporais em relação à exploração do espaço, criando desenhos espaciais a partir do deslocamento do corpo. Por não propor uma lógica interpretativa e racional para suas composições, quando eliminava qualquer tipo de explicação prévia e um sentido dado de antemão, exigia que o público estivesse ativo e engajado no momento, para experimentar o que estava sendo proposto na obra e, assim, pudesse fazer a sua própria leitura (Sontag, 1987). Desta forma, tanto público como artistas, deveriam estar presentes no instante de realização da obra. Por essa perspectiva, Doria (2015) refere-se a uma dramaturgia do espaço associada a uma dramaturgia do público, afirmando que não seria possível separar estas instâncias.

Na obra de Trisha Brown denominada Man Walking Down the Side of a Building de 1970, por exemplo, um bailarino caminha, literalmente, sob a fachada de um prédio. Seu corpo, sustentado pela bacia por equipamentos específicos e cordas, se mantém na posição horizontal em relação ao chão com os pés tocando a parede. Desce lentamente com a frente do tronco voltada para baixo, num movimento de caminhar dos pés na parede do edifício, que agora se torna seu chão. O intuito da diretora norte-americana era de que uma ação natural pudesse ser realizada em um ambiente não-natural, de forma que isso causasse uma fricção, tanto em quem visse o ato quanto em quem o realizava. (Brown, 2020a).

O trabalho Walking on the wall de 1971 é outro exemplo de como a autora utiliza o espaço vertical de uma parede, como no interior de uma galeria de arte, alterando seu sentido primeiro e transformando-o em uma possibilidade de chão onde os bailarinos caminham, correm, saltam e cruzam uns com os outros. Para isso, mais uma vez Trisha Brown traz para a cena uma série de aparatos, como trilhos de correr presos ao teto, cordas e materiais de suporte para os intérpretes, que possibilitam experienciar este espaço incomum (Brown, 2020b). E em Spiral, criado em 1974, os bailarinos andam em torno do tronco de uma árvore de um parque ou da pilastra de um edifício, descendo em espiral, com seus corpos 
paralelos ao solo. (Moore, 2020).

Instigado pela prática da escalada indoor e por esses e outros trabalhos de Trisha Brown, o autor do presente artigo criou em 2012 a intervenção Ao Vestir vertigens, parte de sua pesquisa de mestrado desenvolvida entre os anos de 2012 e 2014, em que contava com um grupo de estudos formado por bailarinos graduandos no curso de dança da universidade. Com utilização de equipamentos de segurança específicos de escalada, além das devidas condutas e treinamento técnico necessários para a prática, os integrantes montavam um guarda-roupa suspenso numa parede de 8 metros de altura. Poder-se-ia conceber que o espaço que utilizavam já continha elementos cenográficos, pois não se tratava de uma parede comum, mas de um ambiente artificialmente construído e adaptado para a prática da escalada esportiva. Possuía saliências de diversos tamanhos, cores e formatos, denominados de agarras, fixadas em grande parte da superfície da parede.

No ambiente da escalada estas saliências têm a função específica de ponto de ponto de apoio, onde os escaladores colocam os pés e as mãos para ascender, rumo à parte mais alta da parede. Mas no universo de criação que se propunha o trabalho ao investigar o espaço vertical, estas agarras não se limitavam a servir somente de apoio. Algumas vezes se tornam uma pedra no caminho do bailarino, derrubando-o ou tirando seu equilíbrio. Outras vezes, eram utilizadas como amparo para outras partes do corpo, para deitar e sentar. E ainda serviam como ancoragem para os objetos que eram fixados. Tornavam-se então parte da cena, dando suporte para que o guarda roupa suspenso pudesse ser construído.

Como exemplo, em uma das cartas elaboradas por um dos integrantes do grupo de estudos, como parte do relato de experiência do trabalho em questão, as agarras foram tratadas como pessoas em que se podia identificar a personalidade ao tocá-las com as mãos. Ele se lembrava da fala de seu avô, de que seria possível reconhecer uma pessoa só pelo aperto de mão. Assim, algumas agarras pareciam o cumprimentam de uma criança, oferecendo uma pequena área de contato, que admitia toque suave e macio, proporcionando calma e bem estar. Outras, eram grandes e se pareciam com pessoas responsáveis, pois sentia-se que 
podia confiar. Mas ainda tinham aquelas que se assemelhavam com pessoas rabugentas, onde ao tocar já te machucavam.

Enfim, percebia-se que neste espaço vertical, como na prática da escalada em ambiente natural, todo o corpo via e se interessava pela ação que realizava. Em consonância com o filósofo e escalador Michel Serres, na prática da escalada “a visão oculta-se sobre o tato" (Serres, 2004, p. 14-15). A visão não se limita aos olhos, mas a partir do contato da pele com a parede, poder-se-ia ver com todo o corpo. Mais que isso, a pele se tornaria extensível, pois se sentia, a partir do toque, integrado com o mundo que habitava.

O trabalho, caracterizado como uma intervenção coreográfica urbana, com duração média de 4 horas, contava com quatro bailarinos/escaladores que tinham o desafio de montar um guarda-roupa, subindo pelas paredes e, utilizando as agarras de escalada como suporte, prender diversos objetos. Carregavam sacolas com roupas, sapatos, adereços e acessórios, que deveriam ser colocados na parede de forma a realizar uma composição plástica. Ao subir, os bailarinos observavam as roupas já fixadas e buscavam criar combinações de vestuário, como se montassem a vitrine de uma loja, seguindo uma lógica estética e/ou funcional. Não se tinha um mapa pré-definido, que estabelecia onde as roupas deveriam ser colocadas. Como num jogo, cada integrante tinha autonomia para criar a sua composição.

Para isso, algumas regras eram definidas. Uma delas era de que os bailarinos não poderiam derrubar as roupas já fixadas, exigindo que seus movimentos fossem precisos e com alto grau de atenção. Este item era fundamental para que se tornasse possível adentrar numa experiência de fluxo, conforme deslinda Csikszentmihaly (2002). Percebe-se que neste tipo de experiência, em que a pessoa está completamente compenetrada no que está fazendo, sem ter tempo nem energia psíquica suficiente para pensar em outra coisa, há ordem na consciência. A informação está congruente com os objetivos e o fluxo da energia psíquica libera-se: 
[...] nesse estado de concentração profunda, a consciência está invulgarmente bem ordenada. Pensamentos, intenções, sentimentos e todos os sentidos estão concentrados no mesmo objetivo. A experiência está em harmonia. E quando terminamos o episódio de fluxo, sentimonos mais 'unidos' do que antes, não só interiormente, mas também no que respeita aos outros e ao mundo em geral. (Csikszentmihalyi, 2002, p. 69).

Após o guarda-roupa suspenso montado, com todos os materiais pendurados, a segunda etapa do trabalho consistia nos artistas subirem e se vestirem suspensos, escolhendo as combinações que thes interessavam, até chegarem ao topo da parede. Deveriam aproveitar as potencialidades daquele espaço incomum para se vestirem de maneiras inusitadas, como colocar uma roupa com o corpo invertido, de cabeça para baixo, ou usar a própria agarra para se ajustar e a parede para se impulsionar a fim de chegar até a próxima roupa a ser utilizada.

No entanto, neste jogo de montar o guarda-roupa suspenso e se vestir de maneiras inusitadas, os performers acabavam realizando movimentos não somente em linha reta, rumo ao topo da parede, mas em ziguezagues, saindo de baixo do ponto fixo da corda que os sustentava. Neste momento, tinham potencialmente o risco de queda, pois caso perdessem o apoio, realizariam um movimento de pêndulo, desenhando um semicírculo na parede, habitando não mais o espaço vertical, mas o espaço aéreo (Millás, 2014), suspensos pela corda, sem tocar mais nas agarras. Desta forma, os performers alternavam entre a utilização do espaço vertical, com o apoio ativo do corpo na parede, e a utilização do espaço aéreo, num voo, tanto em queda para baixo, quanto em pêndulo para os lados, ou salto para fora.

Neste sentido, enfatiza-se que mesmo sendo usados materiais de segurança, como as cordas e ancoragens, existe uma real possibilidade de queda, que pode causar danos aos praticantes. Chocar-se na parede, inverter o eixo do corpo sem querer, cair ou prender-se nos materiais são alguns exemplos. Mas por se ter um duplo treinamento adequado, conforme mencionado anteriormente, que não se trata somente de um treinamento físico, mas de um treinamento afetivo, de escuta, pode-se experienciar o espaço vertical e dele deixar-se ser movido. Nas práticas verticais, que envolvem este tipo de relação com o espaço incomum, acredita-se que seja o próprio risco que motive os participantes, pois exige que estejam atentos e concentrados na atividade, ampliando o conceito de si mesmos no movimento de ascensão em que se colocam voluntariamente. Trata-se de um risco consentido. 
Além disso, os materiais utilizados não seriam somente para segurança dos participantes, mas permitiriam aos bailarinos habitar outros espaços e ter diferentes experiências corporais quando suspensos. Sem o recurso desta tecnologia, não seria possível experienciar o movimento de pêndulo na parede ou as inversões de eixo, ou ainda tornar a parede um chão.

Ao final da intervenção, depois dos bailarinos estarem devidamente vestidos, já no topo da parede, próximos à ancoragem, dois participantes do trabalho abriam um guardachuva, se posicionavam com o tronco paralelo ao solo, com a frente do corpo voltada para baixo e os pés apoiados na parede que agora se tornava seu chão (assim como no caso do primeiro trabalho de Trisha Brown aqui mencionado) e, então, caminhavam mantendo essa postura até chegar ao nível baixo. Ao tocarem o chão, voltavam a ser bípedes, retomando o eixo corporal vertical. Mas após esta viagem, como apresenta Serres (2004), seria melhor dizer que nasciam, não outra vez, e sim pela primeira vez, como bípedes eretos, lidando com a gravidade e percebendo o próprio peso e eixo do corpo.

Diversas foram as experiências corporais vivenciadas pelos integrantes do grupo ao longo da intervenção: subir e descer da parede para fixar objetos; escolher no momento da ação a combinação de vestuário a usar; virar de cabeça para baixo para se vestir; pendular de uma extremidade a outra para alcançar algum utensílio ou por ter perdido o apoio e resvalado; girar com o corpo suspenso; saltar, sentindo-se flutuar por alguns segundos; e suportar a ação da gravidade sobre as costas e toda parte posterior do corpo, quando se caminhava com os pés na parede. Não poderiam terminar da mesma forma que começaram.

Ao final do trabalho, após a experiência de a(fe)tivação em relação ao espaço, frequentemente os integrantes do grupo relatavam sentirem-se mais despertos e transformados. Tinham maior clareza do eixo de seu corpo. Seus sentidos estavam ampliados. Percebiam a gravidade com maior detalhe e sutileza, em cada gesto, a cada passo. Por isso a sensação de, ao retornarem ao chão, não estarem nascendo outra vez, mas pela primeira vez.

Perceber o espaço vertical enquanto fator de a(fe)tivação, é revelar sua dupla potência tanto em ativar quanto em afetar. Proporciona ao praticante adentrar num lugar incomum e experienciar o fluxo que tanto o mobiliza quanto o desloca de sua zona de conforto, revelando outras maneiras de ver e viver o mundo. Exige que o praticante esteja ativo, engajado corporalmente na ação que realiza, e íntegro no momento. Sua 
concentração deve ser plena, perdendo a noção cronológica do tempo, esquecendo dos problemas diários e até mesmo de si. Desfaz-se de uma imagem pré-estabelecida e de uma concepção fechada, para que ao final da atividade possa se perceber diferente. Ao experienciar este espaço incomum, sente-se desperto, com a sensibilidade aguçada e potente corporalmente.

Em Ao Vestir Vertigens, interessava também a possibilidade de alteração da perspectiva do público, por firmar um novo referencial, quando a parede se tornava um chão e vice-versa, permitindo que o mundo fosse visto de outra forma, desacostumando o olhar e conduzindo o espectador a sair do lugar-comum para poder ver por outros pontos de vista. Como diria Manoel de Barros (2010), seria necessário “desinventar”, pois as coisas não querem mais ser vistas da mesma forma.

Em consonância com os trabalhos de Trisha Brown apresentados, realizava-se uma ação cotidiana sob circunstâncias não cotidianas. Deslocava-se uma ação de seu ambiente natural para que outras leituras e mundos fossem possíveis de serem criados. A parede de escalada deixava de ser somente um ambiente de prática esportiva para se tornar campo de atuação, onde os bailarinos criavam suas danças, transformavam e deixavam-se ser transformados pelo espaço. A parede ganhava sentido de guarda-roupa, quando continha os diversos objetos pendurados; de camarim, para que os bailarinos pudessem se trocar; e de rua para caminhar. As agarras concebidas inicialmente como ponto de apoio, com a finalidade dos escaladores subirem ao topo, agora se tornavam utensílios para fixar cabides, cadeira de descanso, obstáculos a serem evitados. Ressignificava-se o sentido tanto do espaço quanto dos objetos.

Buscava-se desinventar enquanto possibilidade de alterar a função primeira a qual as coisas foram concebidas, dando-lhes outros significados. Criava-se estranheza no olhar. Almejava-se fazer um objeto delirar (Barros, 2010), ao perder o sentido para poder ganhar outro. Fazer a parede delirar até se tornar um guarda roupa, por exemplo. Tornar o lugar-parede um espaço a(fe)tivo. Gerar indagações.

No caso desta intervenção, por se estar utilizando a parede externa de um prédio da universidade, próximo à rua, os transeuntes, em seus trajetos cotidianos, já acostumados com uma determinada paisagem urbana, quando se deparavam com a instalação, que lhes causava estranheza, eram convidados a olhar com mais atenção. Algumas pessoas paravam seus trajetos e apreciavam a obra, outras se mantinham em movimento e somente fixavam o olhar na intervenção, ou expressavam em voz alta suas reações, outras 
ainda abordavam os integrantes do grupo para saber mais informações sobre a proposta. A intervenção deslocava seus olhares e gerava curiosidade, tirando-lhes da normalidade e despertando algum tipo de interesse e reação.

Ao Vestir Vertigens permitia que os transeuntes, tornados espectadores, se deparassem com o espaço e fossem por ele convidados a ver melhor. Tratava-se de ressignificar lugares e objetos, invertendo perspectivas e possibilitando outros olhares.

Escutaram-se diversos comentários do público, como de um senhor de idade que se permitiu entrar no jogo e imaginar como usaria o guarda roupa suspenso para se vestir: “Nossa, na minha idade eu só chegaria ali de helicóptero", se referindo a uma roupa pendurada na parte mais alta da parede. Depois observando uma bota posicionada mais próxima do chão, ponderou: "se bem que aquela ali eu até conseguiria... acho que dá para eu me vestir!". Outros reforçavam a transformação feita no espaço: "Eu faço todo o dia o mesmo trajeto e nunca tinha reparado nesta parede". Intrigavam-se também com a impossibilidade criada, pois se era possível vestir-se com os pés no chão, para que subir na parede para fazer isso? Algumas pessoas desafiavam os bailarinos, propondo combinações de roupas para se vestirem, escolhendo aquelas que thes pareciam mais interessantes.

Raro eram os casos que passavam omissos, sem nenhum tipo de reação. Mesmo aqueles que estavam apressados em suas rotinas, eram transportados por alguns segundos para o mundo suspenso criado com o espaço vertical.

Questionava-se sobre o que era possível o artista transformar no espaço, alterando sua função, estética e organização, e o que o espaço transformava no artista e no público, alterando a percepção que tinham de si mesmos e do mundo. No contexto de Ao Vestir vertigens, a parede não se tornava um empecilho, mas, ao contrário, dava suporte para a criação cênica e interação dos bailarinos com o espaço e transeuntes, de forma que outras perspectivas fossem possíveis. Para um escalador, a parede ou montanha não o impede de prosseguir, mas trata-se justamente de uma rota, oferece uma possibilidade de trajeto vertical, em que ascende rumo ao cume. O escalador, assim como os performers, não busca o espaço somente como suporte para sua prática, mas como uma possibilidade de se transformar, gerando um campo a(fe)tivo que permite ver a si e ao mundo sob outra perspectiva. O praticante deixa de lado uma concepção de si para que outras possam ser criadas. 

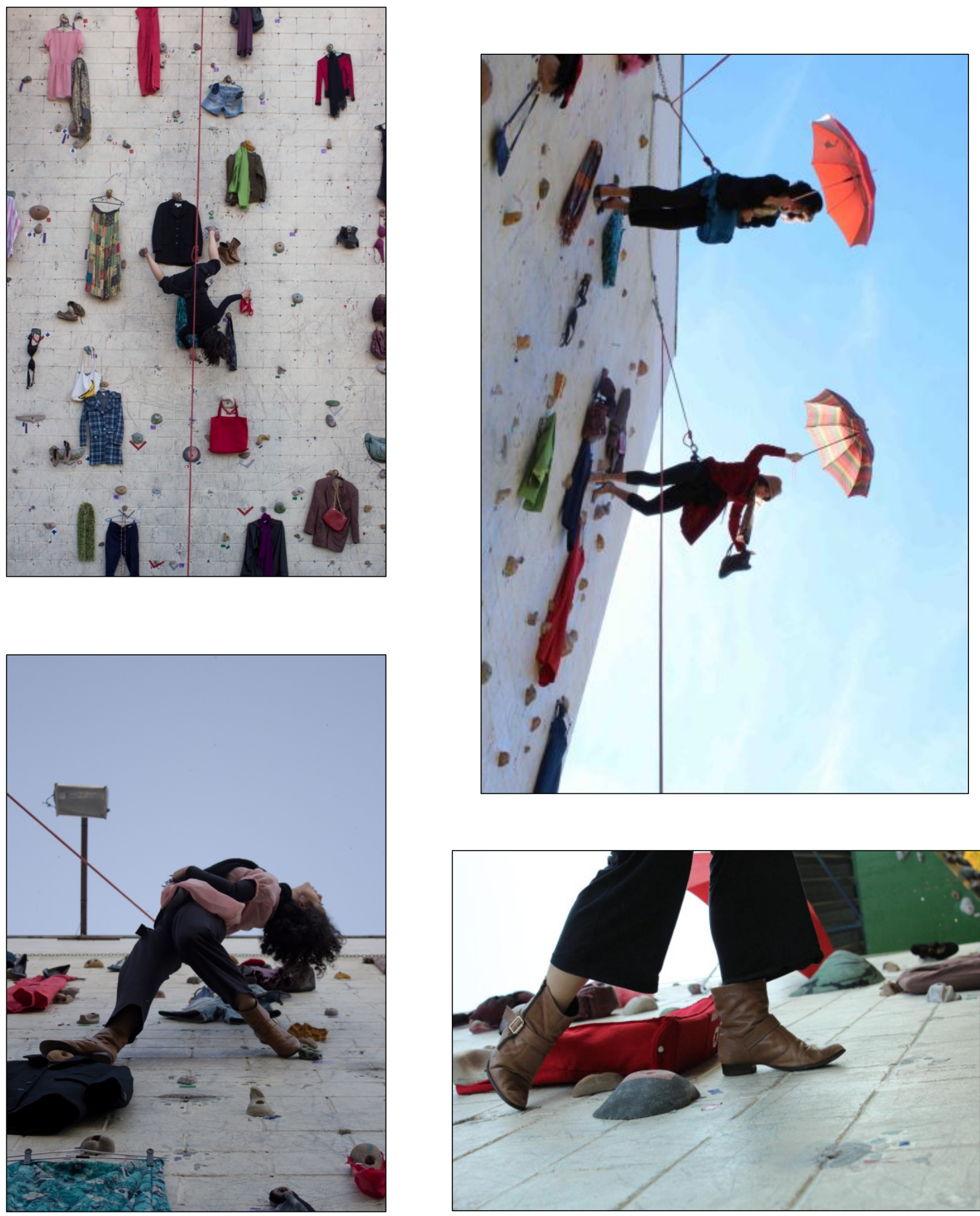

Fotos: Pedro Langella 


\section{Ausência/Presença ${ }^{3}$}

Seguindo a lógica de uso do espaço vertical por meio da apropriação de uma parede, iniciada no trabalho Ao Vestir Vertigens, e ainda em busca do corpo-emfluxo como potência de criação e transformação, quando o praticante sente que parte de si desaparece para que possa ter outras concepções de si e do mundo, em 2017 foi elaborada a performance Ausência/Presença.

Este trabalho nasceu dentro de um contexto acadêmico, em uma disciplina de pós-graduação em artes, na qual se tinha como proposta o debate crítico sobre o repertório artístico dos participantes, que seriam atravessados pelos trabalhos e comentários dos outros colegas, para que ao final pudessem apresentar suas obras ao público em uma exposição com duração de três dias, que seria realizada em uma galeria de arte da cidade.

Como a disciplina em questão era oferecida dentro de um programa essencialmente das artes visuais, o autor, um artista da cena, viu-se cercado de artistas plásticos, dentre pintores, gravuristas, fotógrafos e escultores, que utilizavam de diversas técnicas, desde o bordado e a costura até a vídeoinstalação, com propostas de construção de suas obras a partir de sua materialidade, visível aos olhos. Neste contexto, tornou-se evidente que a arte cênica que o autor se utilizava era efêmera por natureza, pois vídeos e fotos seriam apenas registros e não a obra em si, perdendo o que o autor considerava como mais importante para seu trabalho: a presença do corpo em cena, quando a obra se dá a partir do "caráter direto da experiência", no qual se pode observar a "presentidade" e o "estado de ser" do performer, conforme evoca Robert Morris (2006). O foco estaria no momento da cena, na força gerada naquele instante e não na sua representação ou possível fixação no tempo e espaço, pois em consonância com o autor: "o espaço real não é experimentado a não ser no tempo real." (Morris, 2006, p. 404).

Para maiores informações sobre este trabalho, com vídeos e fotos, pode-se acessar o link: https://claudiamillas.wordpress.com/espetaculos/ausencia-presenca/ 
Em contraposição com o material que dura, para apresentar seu trabalho o autor buscou uma forma de evidenciar a efemeridade característica de sua arte, utilizando seu próprio corpo para compor e decompor o espaço. O trabalho proposto para desenvolvimento na disciplina foi uma performance com trinta minutos de duração, que seria realizada em um dia específico da exposição, suscitando algumas questões acerca desta fricção causada entre as áreas das artes visuais e das artes cênicas: antes e após a ação artística, o que estaria sendo exposto? A ausência? Como expor a ausência? Após a realização da performance, seria possível perceber que materialmente algo teria acontecido, como os rastros deixados, mas existiria algum campo de forças invisíveis, mas perceptíveis, criado no espaço? Algo permaneceria? Assim, o paradoxo de não trabalhar com um material, mas ter uma obra "exposta" numa galeria de arte instigou sobre a questão da presença e da ausência. Interessava verificar a qualidade da ausência, tanto anterior à realização do trabalho, enquanto haveria apenas uma marcação na parede com nome do autor e obra, um vazio em potencial aguardando algo, em latência; quanto da ausência após a performance, que estaria habitada pela presença anterior e pelos rastros e interferências deixados no espaço, que o teriam modificado em nível sensível e formal. E a qualidade da presença ao longo da ação, que estaria habitada de ausência, por tentar se aproximar do corpo-em-fluxo, que não impõe alguma coisa ou busca confirmar algo de antemão, mas se abre ao encontro e aos possíveis, ainda não dados.

No primeiro trabalho analisado, Ao Vestir Vertigens, percebeu-se o espaço como catalisador da criação cênica, que tensionava os artistas a realizarem ações, a se transformarem e verem a si e ao mundo sob outra perspectiva. Deslocava-se o sentido de objetos. Realizavam-se ações ordinárias em espaços extraordinários, desacostumando o olhar do público e convidando-o a entrar no jogo de criação de sentido da obra. Neste segundo trabalho o que estava em jogo era tanto o espaço mobilizador, quanto a interação do performer que exploraria a parede em sua concretude, não sendo necessária a utilização de equipamentos específicos da escalada como as cordas e pontos de ancoragem, mas ferramentas artesanais. Buscava-se pela força gerada a partir do encontro e a percepção do que se 
sustentava no espaço após o acontecimento, sendo possível de permanecer enquanto obra até o final da exposição.

O autor foi impulsionado a realizar uma obra fora dos moldes convencionais de apresentação cênica, em que o espectador vai até o local para ver o espetáculo, do início ao fim, com tempo determinado. Neste caso, a obra não se configuraria como um espetáculo, mas compartilhando a ideia de Visconti (2014), seria como nas "práticas artísticas 'livres' da obrigação de produzir objetos concretos" (Visconti, 2014, p. 132) ou ainda uma "obra que não visa à produção de um objeto artístico, mas à criação de veículos entre pessoas." (Visconti, 2014, p.135).

Ausência/Presença então se configurou na possibilidade de delimitar o espaço da parede da galeria destinado ao trabalho, utilizando-se de um martelo, pregos e uma linha preta fina, com intuito de emoldurar o vazio (a ausência), revelando uma dança rústica e artesanal. Em seguida, buscou-se habitar o espaço vertical da parede, sentindo o campo de forças que continha para se deixar tornar parte dele, sendo o artista transformado ao longo da ação, num movimento de a(fe)tivação. Para isso, trabalhou-se com a qualidade do corpo-em-fluxo, quando o praticante sente desaparecer, tamanha a concentração e o engajamento em cena (presença habitada de ausência). E para finalizar, deixou-se o espaço, já transpassado por ele, percebendo em si mesmo e no próprio ambiente o que havia sido construído, a partir das marcas visíveis e invisíveis geradas do encontro, que permaneceriam após a performance (ausência habitada de presença). 

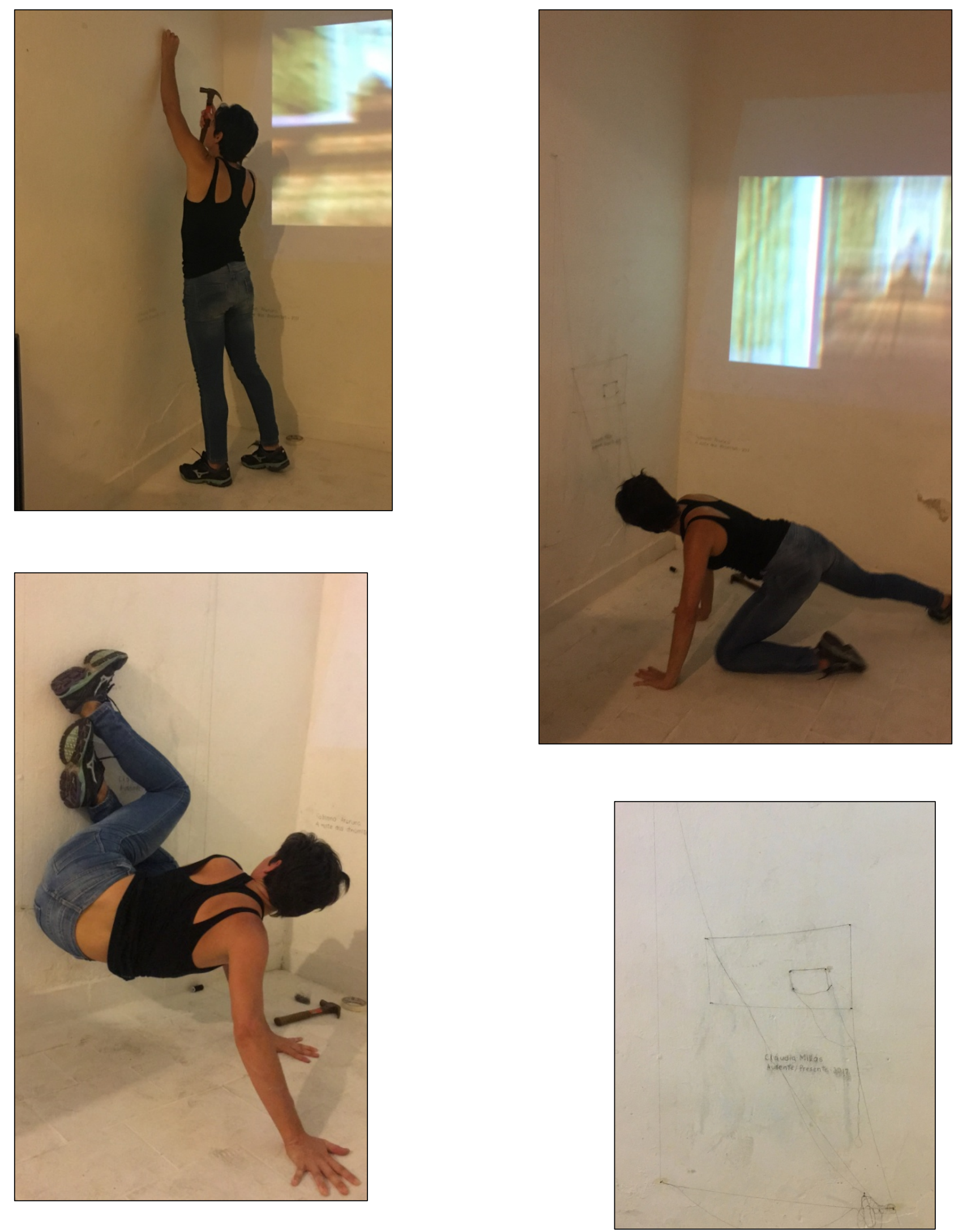

Fotos: Fernando Barcellos 


\section{Sobre o que desaba e que não sei dizer ${ }^{4}$}

Este é o último trabalho da trilogia apresentada, sendo o mais recente, e tendo passado por diferentes municípios de criação, espaços de interferência e apresentação, em parceria com profissionais que estiveram na figura de provocadores, orientadores e diretores.

Percebe-se que estão contidas as sementes das criações anteriores e de seus disparadores, sendo um "fechamento" para a criação cênica de relação entre a dança e a prática da escalada. Impelido pela experiência de criação da performance Ausência/Presença, o autor via-se instigado a transformar o espaço, materialmente, plasticamente, e perceber os rastros deixados. Não seriam necessários novamente os equipamentos para trabalho em altura, como cordas e pontos de ancoragem. Trabalhar-se-ia na relação direta entre chão e parede. Pensava-se nas escritas criadas do corpo no espaço. Também contaminado pelo uso de espaços não convencionais e possibilidades de inversão do olhar, devido à prática de escalada, já presente desde o desenvolvimento de Ao Vestir Vertigens, almejava-se criar outros pontos de vista, podendo deslocar a cena e, consequentemente, o espectador. Além disso, vislumbrava-se a apropriação da experiência de fluxo (Csikszentmihalyi, 2002) como forma de se transformar ao longo da ação e, de alguma forma, desprender-se de contornos e ideias fixas que paralisavam, podendo assim desaparecer para poder ganhar outras percepções e emancipar-se de uma condição.

O trabalho iniciou-se em 2018 com estudos de movimento partindo do desamparo como potência de criação, conforme expõe Safatle (2015), numa condição corporal de desabamento, quando se sentia perder os apoios, como se esses fossem retirados, ou quando o próprio bailarino, já viciado na condição, os tirava. Era uma condição que o fazia passar horas em movimento, relacionandose com o chão a partir de quedas contínuas, como se não conseguisse (ou não

Para maiores informações sobre este trabalho, com fotos e vídeos, pode-se acessar o link: https://claudiamillas.wordpress.com/espetaculos/sobre-o-que-desaba-e-que-nao-sei-dizer/ 
quisesse) sair daquele lugar. O autor sentia que era esse estado corporal que o animava, fazendo com que pudesse explorar uma qualidade corporal particular e ainda desdobrá-la em outras ações.

Esta qualidade de movimento gerada pela sensação de desamparo não se limitou somente a uma fase do trabalho, mas permeou todo o processo criativo. Como uma condição corporal, gerou a primeira cena do espetáculo e funcionou como disparadora para as demais. Conforme deslinda Safatle (2015), sentir-se desamparado seria sair do lugar de determinação e identificação, que edificam o ser em um lugar único e comum, para poder se despossuir de seus predicados, das possibilidades de definição, e se deixar transformar ao longo da ação, ser corpo errante, sem paragem, em processo de criação.

O figurino concebido para o espetáculo era com o máximo possível do corpo nu, para que a pele, os músculos e o corpo enquanto materialidade, com sua carne, fossem vistos. Usava-se apenas um pequeno short preto e um tule, também preto, em volta do crânio, criando uma deformidade na cabeça e escondendo o rosto. Interessava não só o embaralhar dos sentidos do público e a inversão da perspectiva, de forma que não se soubesse mais o que era chão e o que era parede, mas também que o corpo em cena não pudesse ser facilmente decifrado. Neste sentido, no início do espetáculo utilizava-se ainda uma luz cênica mínima, somente vinda das frestas da janela da sala de apresentação, fazendo com que a figura em cena não pudesse ser vista com nitidez e então identificada.

Alguns espectadores relataram terem tido a nítida impressão que a figura em cena era de um determinado gênero e se surpreendido, num segundo momento, ao perceberem que se tratava do contrário. Outros, afirmavam terem perdido a referência binária homem/mulher e haviam identificado um ser sem gênero. E ainda aqueles que já conheciam o artista e sabiam que se tratava de um espetáculo solo, se mantiverem em dúvida no início, questionando suas preconcepções. Interessava justamente criar este lugar de dúvida e estranheza, que exigia atenção no olhar e engajamento por parte do público que não poderia ficar passivo e firme em suas concepções. O mesmo se dava em relação ao jogo com o espaço, quando poder-se-ia duvidar se o amparo ao qual o bailarino de 
deitava em cena era um chão ou uma parede.

Em parceria com um pesquisador, artista e professor de dança em uma escola de educação básica, como orientador e provocador do processo inicial de construção do trabalho, passou-se a ensaiar na sala em que este ministrava suas aulas na escola: um ambiente voltado para a educação infantil, que permitia alterações na disposição de objetos e interações no espaço, com recursos para que o lugar pudesse ser transformado a partir das práticas artístico-pedagógicas desenvolvidas - diferente das salas de ensaio de dança, sejam públicas ou particulares que, de maneira geral, com suas paredes brancas, pretas ou espelhadas, não podem ser transformadas.

Dispuseram-se então a pensar/fazer interações do corpo no espaço, como uma das motivações de interferência trazidas a partir do trabalho anterior, Ausência/Presença. Em um dos laboratórios criativos o autor teve a oportunidade de desenhar e pintar nas paredes enquanto dançava, deixando marcas no espaço. No dia seguinte, quando os alunos chegaram à sala e viram aqueles registros nas paredes, logo se dispuseram a fazer outros desenhos dando continuidade, de forma espontânea, ao trabalho. Criou-se, assim, um espaço de interação e diálogo silencioso, em que a imagem que um produzia incitava ao outro e vice-versa.

Foi assim que se passou a convidar o público, ao final da obra, a entrar no espetáculo, compondo com o artista, para que pudesse também desenhar na parede e dar continuidade ao trabalho. O espaço vertical, a partir da utilização da parede em cena, se tornou espaço produtivo, enquanto potência de criação compartilhado, em que se podia transformar, subvertendo normas impostas e regras pré-estabelecidas de utilização do ambiente. Como espaço "desamparador", que mobiliza e abre para o encontro com o Outro, num circuito de afetos (Safatle, 2015), tornou-se possível a criação de novos mundos. Gestos se encontravam na parede a partir das marcas deixadas, gerando um fluxo de rastros humanos. O desenho realizado por um, motivava o desenho do próximo, assim como a ação cênica e vice-versa. A parede se tornou lugar de encontro e criação.

Neste sentido, o desejo era poder utilizar lugares de apresentação, fosse uma 
galeria de arte ou sala multiuso, que pudessem ser transformados "permanentemente", como se o espetáculo gerasse uma obra visual que ficaria exposta nos dias subsequentes e que continuaria se desdobrando a partir da interferência de outras pessoas que, mesmo sem terem assistido à ação cênica, pudessem dar continuidade ao desenho criado. Desta forma, na obra em questão, a parede foi entendida como parte do cenário do espetáculo, que era construído ao longo da ação de cena, não somente pelo artista, mas por aqueles que observavam, partilhavam e também faziam o trabalho acontecer.

Os desenhos do bailarino em cena eram criados conforme as pulsões e atravessamentos com o próprio jogo de luz e sombra que se fazia, das ações físicas, da relação com o público e o espaço. Não se tinha uma imagem específica a seguir, a priori, mas diferentes qualidades de movimentação e motivações para desenhar na parede e usar este recurso como forma de criação e diálogo com os presentes.

A partir de 2019 trabalhou-se conjuntamente com outro artista e professor de acrobacias, que passou a assinar a obra como diretor, focando na construção da dramaturgia cênica, lapidando o entrelaçamento das camadas da trilha sonora, das ações físicas, do figurino e indumentária, do cenário e da iluminação cênica.

Como necessidade de dialogar com a parede enquanto espaço de a(fe)tivação, em relação ao trabalho Ao vestir Vertigens, e a partir da memória das vivências com a escalada, como lugar transformador e libertador, buscou-se (re)significar sua imagem. O autor, intrigado com as possíveis leituras do que poderia vir a ser uma parede, seja como algo que bloqueia e impede a passagem, por sua estrutura que delimita um espaço para fechá-lo ou protegê-lo, seja por se tornar um lugar de criação e transformação, em que se pode desenhar, dançar, descansar ou escalar, o trabalho desenvolveu-se a partir dos inúmeros exemplos de paredes e muros com valores simbólicos e religiosos ao longo das diversas culturas no mundo. Assim, poder-se-ia tomar como exemplos o Muro das Lamentações em Jerusalém, o Muro de Berlim, a Muralha da China, as fachadas de prédios que se tornam painéis de grafite, revelando um mundo colorido e mágico para as cidades cinza, ou as pinturas rupestres nas paredes das diversas 
formações geológicas que os povos usavam para registrar, guardar, comunicar ou expressar.

A parede foi ganhando, então, outros contornos, que não só de obstáculo, mas de afeto. Neste caso, ao contrário, tinha-se o chão como espaço hostil quando o bailarino perdia os apoios e a parede como espaço seguro, de conforto, que guardava as marcas do corpo suado, do giz traçado e dos pés apoiados. O artista em cena transitava entre chão e parede. Ora escalava o chão, ora caminhava na parede. Algumas vezes tinha o corpo paralelo ao chão, outras vezes mantinha a posição ereta, mas com a cabeça para baixo.

Por meio de debates e bate-papos realizados com o público ao final dos espetáculos, constatou-se que no jogo de inversão do olhar, ao trazer a referência da parede como um chão, onde era possível se apoiar e deitar, não era somente a ação que se deslocava e era vista de outra forma, mas o próprio público sentia-se deslocado. Algumas pessoas presentes afirmaram terem sentido uma espécie de estranheza ao ver algumas cenas do trabalho, quando tinham a nítida impressão que o bailarino, ao se estender na parede, estava deitado em um chão. Percebiamse então vendo a cena de cima, e se perguntavam se estariam eles mesmos flutuando. Isto criava um momento de dúvida nos espectadores, que eram convidados a se perceber também de outra forma.

Sem o uso de equipamentos e materiais de segurança, era possível criar uma mudança de perspectiva, que exigia engajamento corporal também daqueles que viam. Não permaneciam sentados no mesmo lugar. Eram movimentados pelo jogo espacial que se fazia. Assim, percebia-se que o fator de a(fe)tivação não se dava somente com o artista em cena, mas com o público que era convidado a olhar com mais atenção, a duvidar do que estava vendo e ressignificar seu próprio lugar. Transformar a parede em chão e vice-versa não alterava somente a relação do bailarino com o espaço, mas a relação do público consigo e com a obra. 

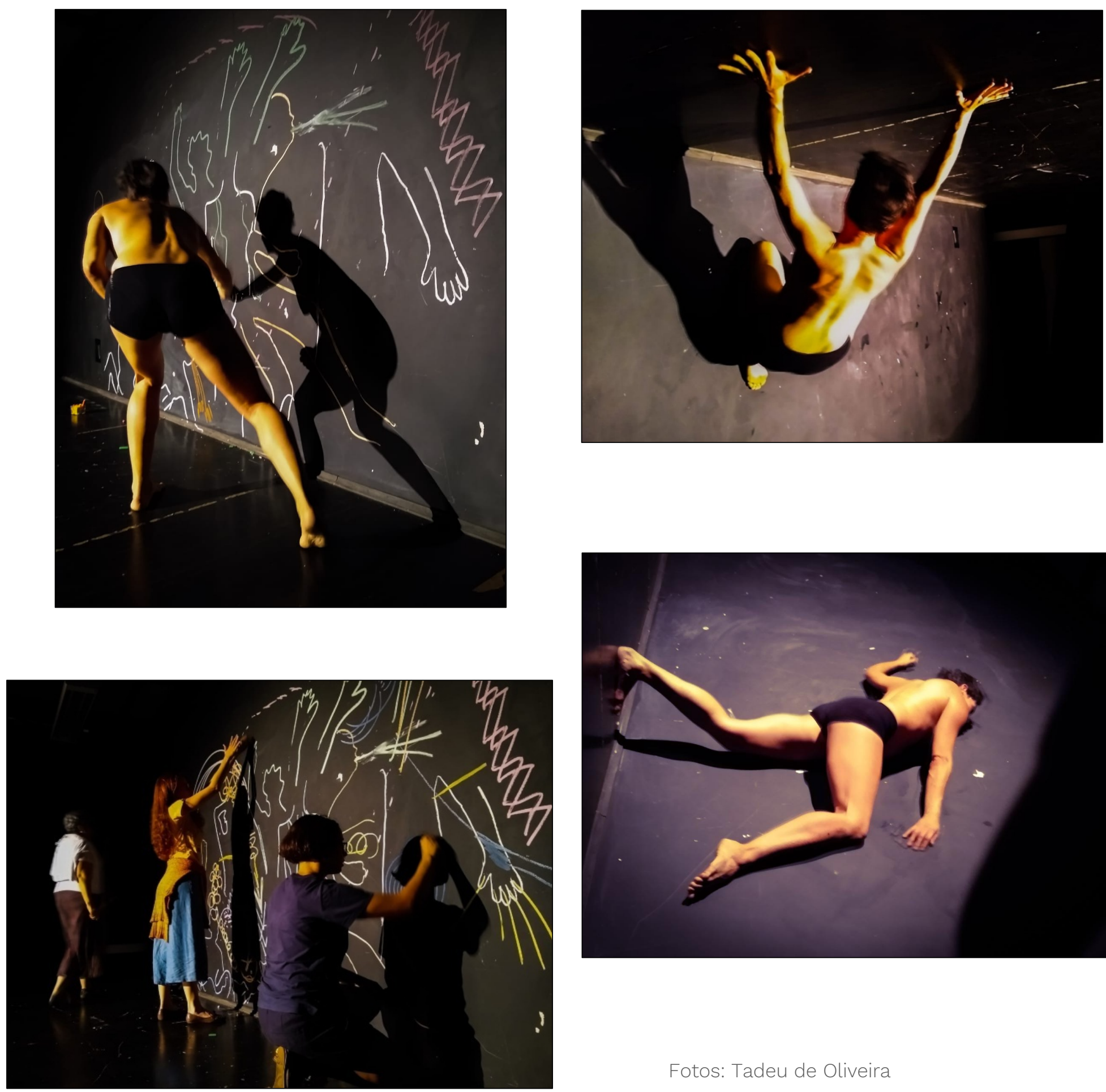

Fotos: Tadeu de Oliveira 


\section{Considerações finais}

Pôde-se observar que a experiência com a prática da escalada foi o elemento chave para criação das obras analisadas, tendo instigado o uso do espaço vertical por meio da apropriação de uma parede em cena e evidenciado questões pertinentes ao campo da dança, seja ela circunscrita no âmbito formal, seja no trabalho de percepção de forças e qualidades de presença. No contexto das obras analisadas, constata-se que a relação entre dança e escalada foi se transformando de um interesse no nível composicional da obra, enquanto estética criada, ao entendimento das práticas como possibilidades de emancipação e transformação dos praticantes, tendo o espaço vertical como catalisador. Identifica-se que cada nova obra foi contaminada pela anterior e impulsionada por outra vertente e perspectiva de abordagem de uso do espaço.

Em Ao Vestir Vertigens, perquiriu-se o espaço vertical enquanto possibilidade de criação de novos mundos, transformando uma parede de escalada em um guarda-roupa suspenso. Deslocou-se uma ação de seu ambiente natural para que outras leituras fossem possíveis de serem criadas. Buscou-se o "desinventar" enquanto possibilidade de alterar a função primeira a qual as coisas foram concebidas, dando-lhes outros significados. Criou-se estranheza no olhar e indagação no público, que foi convidado a ver com mais atenção, desacostumando o olhar, percebendo o espaço de outra forma.

Já em Ausência/Presença, o espaço vertical foi explorado sem recursos materiais e equipamentos de segurança para trabalho em altura, focando nas interferências causadas no espaço e na percepção do que poderia o espaço causar no artista em ação. Observou-se três fases do espaço ao longo da performance: anterior ao acontecimento proposto, como um espaço em latência, habitado de ausência; ao longo da ação, o espaço em transformação; e após todas as intervenções ocorridas, via-se na ausência do performer a presença do acontecido, tanto com os rastros deixados, quanto com o campo de forças criado.

E no último espetáculo analisado, Sobre o que desaba e que não sei dizer, 
também sem a necessidade de aparelhos e materiais de segurança, percebeu-se que ao alterar a perspectiva do espaço, não era somente a ação que se deslocava e era vista de outra forma, mas o próprio público sentia-se deslocado. O espaço dançava o bailarino e os espectadores, brincando com a inversão do olhar. Os signos e significados da parede também eram redimensionados, trazendo outras leituras e possibilidades. Tratava-se de investigar o espaço como fator de a(fe)tivação, que mobiliza e afeta, tanto ao artista em cena quanto a quem assiste a ação, exigindo engajamento corporal e integridade.

Percebeu-se o espaço enquanto um campo de forças invisíveis, mas perceptíveis, com as quais se interage. Ou seja, poder-se-ia pensar que o próprio espaço é que moveria o bailarino, que o dançaria em cena, que seria seu parceiro e também sua motivação. A partir de uma abertura, quando se esquece de si mesmo, daquilo que define e enrijece o ser em uma posição, para permitir-se ser atravessado pelas forças presentes no espaço, é que o bailarino se conectaria numa tríplice vertente (consigo, com o outro e com o meio), em movimento de expansão e integração. Assim, sentir-se-ia parte de algo maior, ampliando seu corpo e se abrindo para o presente, permitindo que algo aconteça e altere a concepção que tem de si mesmo, emancipando-se de uma condição e transformando-se ao longo da ação.

A partir da descrição dos três trabalhos, análise das imagens de registro e relato do público, pôde-se constatar que o espaço, enquanto lugar de a(fe)tivação, tanto por ser ativo quanto afetivo, se transformou. Observa-se que simbolicamente a mesma parede se tornou um muro, que bloqueava e cerceava, impedindo passagem e tampando um campo de visão, como também uma casa, morada, que resguardava, protegia, legitimava e ampliava a ação. A parede se tornou ponte e parada. Assim, poder-se-ia conceber o espaço como lugar de afeto e ativação, por ter em si tanto a potência de mobilização sensível quanto a capacidade de se transmutar. 


\section{Referências}

BARROS, Manoel de. Poesia completa. São Paulo: Leya, 2010.

BROWN, Trisha. Repertory: Man Walking Down the Side of a Building (1970). Site official TBDC: Trisha Brown Dance Company. Andradas-MG, 27 junho 2020a. Disponível em: https://trishabrowncompany.org/repertory/man-walking-downthe-side-of-a-building.html?ctx=title Acesso em: 27 jun. 2020.

BROWN, Trisha. Repertory: Walking on the Wall (1971). Site official TBDC: Trisha Brown Dance Company. Andradas-MG, 27 junho 2020b. Disponível em: https://trishabrowncompany.org/repertory/walking-on-the-wall.html?ctx=title Acesso em: 27 jun. 2020.

CSIKSZENTMIHALYI, Mihaly. Fluir: a psicologia da experiência Optima, medidas para melhorar a qualidade de vida. Lisboa: Relógio D’água Editores, 2002.

DAFLON, Cintia Adriane de Aquino; DAFLON, Flavio Henrique Alves. Escale melhor e com mais segurança: manual de técnica de escalada. Rio de Janeiro: Companhia da Escalada, 2016.

DORIA, Gisela. (de)Composição e produção de sentido: dramaturgias na dança contemporânea. 2015. Tese (Doutorado em Artes da Cena) - Instituto de Artes Universidade Estadual de Campinas, Campinas SP, 2015.

FLORES, Lito Tejada. The Games Climbers Play. Londres (Inglaterra): Diadem Books Ltd., 1978.

LABAN, Rudolf . A Vision of Dinamic Space. Londres: Laban Archives \& The Falmer Press, 1984.

LOUPPE, Laurence. A Poética da Dança Contemporânea. Lisboa: Orfeu Negro, 2012.

MILLÁS, Cláudia Regina Garcia. Trajetórias de risco, treinamento e criação: experiências vividas nos espaços vertical e aéreo. Campinas - SP, 2014. Dissertação (Mestrado) - Instituto de Artes, Universidade Estadual de Campinas.

MOORE, Nancy. Repertory: Spiral (1974). In Site Oficial TBDC: Trisha Brown Dance Company. Andradas-MG, 27 junho 2020. Disponível em: https://trishabrowncompany.org/repertory/spiral.html?ctx=early Acesso em: 27 jun. 2020.

MORRIS, Robert. O tempo presente do espaço. In Escritos de artistas: anos 60/70. Rio de Janeiro: Jorge Zahar Ed., 2006. 
NESS, Sally Ann. Choreographies of landscape: signs of performance in Yosemite National Park. Nova lorque: Berghahn Books, 2016.

SAFATLE, Vladimir. O circuito dos afetos: corpos políticos, desamparo e o fim do indivíduo. São Paulo: Editora Autêntica, 2015.

SERRES, Michel. Variações sobre o corpo. Rio de Janeiro: Bertrand Brasil, 2004.

SONTAG, Susan. Contra a interpretação. Porto Alegre: L\&PM, 1987.

VISCONTI, Jacopo Crivelli. Novas derivas. São Paulo: Martins Fontes, 2014.

Recebido em: 30/06/2020

Aprovado em: 30/07/2020 